\title{
DC-DC Converter Based on PID Controller for Voltage Step- Down Application
}

\author{
Ankita Pandey ${ }^{1}$, Dr. Dharmendra Singh ${ }^{2}$
}

\begin{abstract}
This paper present a pulse width modulation non-isolated buck converter based on PID controller. The buck converter constituted by one Gto, one inductor, one capacitor and load resistor. In this the buck converter connected to the PID controller, PID controller calculate an error value as the difference between a measured process variable and a desired set point. The proportional $P$ depends on the present error, integral I accumulate the past error, derivative D predict the future error. The performance of buck converter has been studied and is undertaken for their theoretical verification and graphical representation.
\end{abstract}

Keywords: dc-dc converter, PID, pulse width modulation, buck converter

\section{Introduction}

Pulse-width modulation (PWM) converter are mostly used in dc-dc conversion application. Widespread application of dc-dc converter include ups, variety of electronic system, energy system of telecommunication, systems of utilization of solar system, dc motor drivers. Also DC-DC converters are often found as basic building blocks for other types of power converters. Buck converter is one of the most important components of circuit it converts voltage signal from high de signal to low voltage. By the help of buck converter we achieve the better efficiency of power conversion. In this the high speed switching device are placed. In this paper work performance of buck converter is analyzed. The circuit may consist of nonlinearity like delay, hysteresis etc. and because of this output voltage is not constant.

A PID controller is a control loop feedback mechanism mostly used in industrial control system. A PID controller calculates an error value as the difference between a measured process variable and a desired set point. The controller attempts to minimize the error by adjusting the process through use of a manipulated variable.

The PID controller algorithm involves three separate constant parameters, and is accordingly sometimes called three-term control: the proportional, the integral and derivative values, denoted P, I, and D. Simply put, these values can be interpreted in terms of time: $P$ depends on the present error, I on the accumulation of past errors, and $\mathrm{D}$ is a prediction of future errors, based on current rate of change. ${ }^{[1]}$ The weighted sum of these three actions is used to adjust the process via a control element such as the position of a control valve, a damper, or the power supplied to a heating element. For a discrete time case, the term PSD, for proportional-summation-derivative, is often used.

A PID controller relies only on measured process variable making it useful converter. By tuning the three parameter of the PID controller, the controller provide the control action designed for specific requirement. The response of the controller can be describe in terms of responsiveness of the controller to an error, the degree to which the controller overshoots the set-point, and the degree of the system oscillation. The use of PID algorithm for control does not guarantee optimal control of the system and system stability. Some applications may require using only one or two terms to provide the appropriate system control. This is achieved by setting the other parameters to zero. A PID controller will be called a PI, PD, P or I controller in the absence of the respective control actions. PI controllers are fairly common, since derivative action is sensitive to measurement noise, whereas the absence of an integral term may prevent the system from reaching its target value due to the control action.

\section{The DC-DC Converter Buck Converter}

The fig. 2.1 shows the dc-dc buck converter. In the buck converter the ac source connected to the diode rectifier and it use as a controlled switch to elicit unidirectional power flow from input to output. The one inductor and one capacitor are use to store and transfer the energy from input to output. The voltage and current waveform are smooth by filter. The circuit is assumed to be operating in continuous condition mode $(\mathrm{CCM})$. The capacitor is large enough to offer a constant output voltage.

In the description of converter operation, all the component like inductor, capacitor etc. are assumed to be ideal and the converter operates in CCM. In the CCM, in inductor the current flows continuously over one switching period. In the buck converter the operation according to switching function, the switch is either on or off and this results in two circuit state. when the switch is turn on this is first subcircuit state, the diode is reverse biased and the inductor current flow through the switch. When the switch is turn off this is the second sub-circuit state, current freewheels the diode, which is shown in Fig.2.3

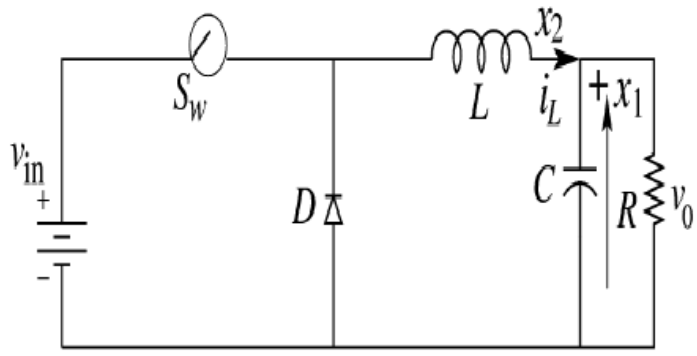

Figure 2.1: DC-DC Buck converter 


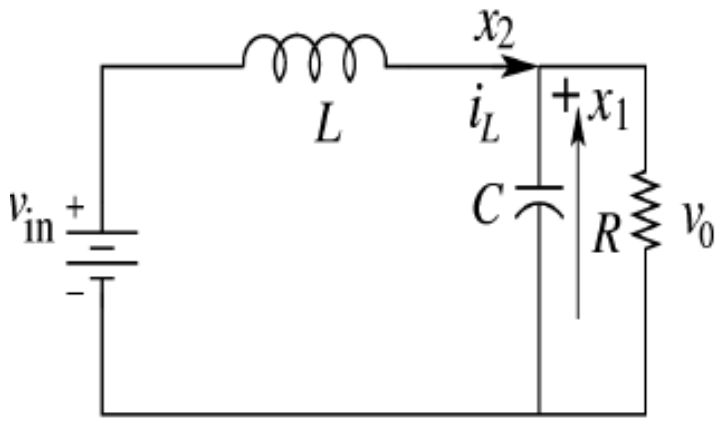

Figure 2.2: Turn On Switch

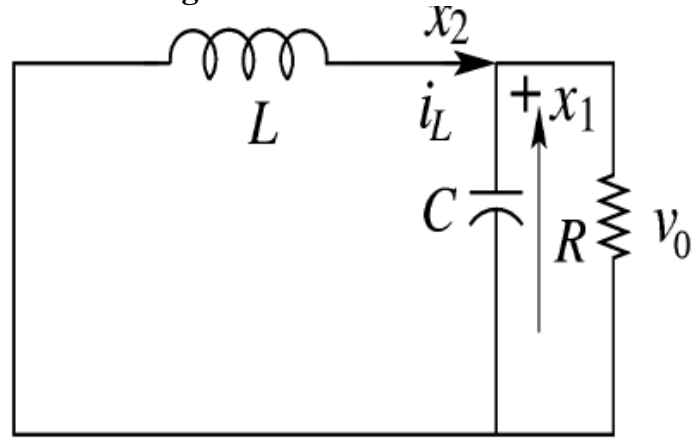

Figure 2.3: Turn Off Switch

\section{Proportional, Interagal and Derivative Controller (PID)}

All the three control strategies are combined to get PID controller and it use to control the over steady state and transient error. In this the control error is a linear combination of error. The PID is a combination of all control component.

In order to get acceptable performance the constants KP, KD and KI can be adjusted. This adjustment process is called tuning the controller. Increasing KP and KI tend to reduce errors but may not be capable of producing adequate stability. The PID controller provides both an acceptable degree of error reduction and an acceptable stability and damping. Fig. 3.1 shows the block diagram of PID controller.

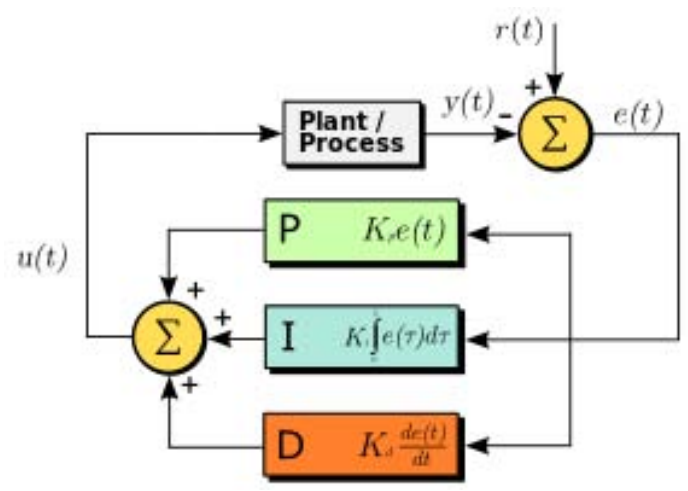

Figure 3.1: Block diagram of PID controller

\section{Control Method}

In this some methods that can be used to control DC-DC converters and the disturbances that have influence on the behaviour of the converter and its stability. The feedback signal may be the output voltage, the inductor current, or both. The feedback control can be either analog or digital control.

\section{Conclusion}

This paper discuss the performance of buck converter and PID controller. By the help of PID controller we achieve the better performance of buck converter. The proposed topology and control technique can be promising solution for high step-up application.

\section{References}

[1] Shelgaonkar (Bindu) Arti Kamalakar, N. R. Kulkarni, "PERFORMANCE VERIFICATION OF DC-DC BUCK CONVERTER USING SLIDING MODE CONTROLLER FORCOMPARISON WITH THE EXISTING CONTROLLERS - ATHEORETICAL APPRO International Journal of Advances in Engineering \& Technology, Jan 2012.

[2] M.Ahmed, M.Kuisma, P. Silventoinen, "Implementing Simple Procedure for Controlling Switch Mode Power Supply Using Sliding Mode Control as a Control Technique", XIII-th International Symposium on Electrical Apparatus and technologies (Siela). May 2003, pp 9-14, Vol. 1

[3] Hongmei Li and Xiao Ye "Sliding-Mode PID Control of DC-DC Converter", 5th IEEE Conference on Industrial Electronics and Applications.

[4] V.I.Utkin, Sliding modes and their application in variable structure systems, MIR Publishers, Moscow, 1978

[5] G. Spiazzi, P. Mattavelli, L. Rossetto, L. Malesani, "Application of Sliding Mode Control to Switch-Mode Power Supplies," Journal of Circuits, Systems and Computers (JCSC), Vol. 5, No. 3, September 1995,pp.337-354.

\section{Author Profile}

Ankita Pandey is pursuing m.tech (power system) from Dr. C.V. Raman University Bilaspure. She has completed B.E. (Electrical Engineering) from C.S.V.T.U. Bhilai (C.G.), India

Dr. Dharmendra Singh: H.O.D. Electrical and Electronics department, Dr. C.V. Raman university, bilaspure. Recently he has done his Phd from Dr. C.V.Raman university bilaspure (C.G.), India 